LA-UR- 97- - 4061

Approved for public reloase; distribution is unimitiod.

\author{
Title: SIMULATIONS OF THE LANL REGENERATIVE \\ AMPLIFIER FEL \\ CONF- $970885 \ldots$ \\ AECEIVED \\ FFR 021998 \\ OSTI \\ Author(s): M. Kesselring, Monterey, CA \\ W. B. Colson, Monterey, CA \\ R. K. Wong, Monterey, CA \\ R. L. Sheffield, LANSCE-4 \\ Submitted to: \\ 1997 Free-Electron Laser Conference \\ Beijing, China \\ August 25-29, 1997
}

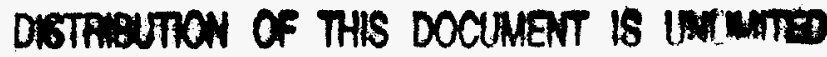

\section{MASTER}

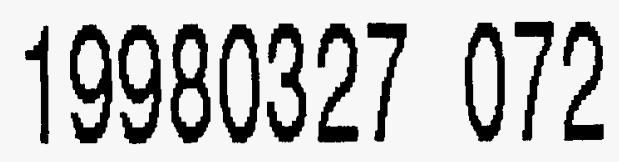

\section{Los Alamos}

NATIONAL LABORATORY

Los Aamos National Laboratory, an affirmative action/equal opportunity employer, is operated by the University of California tor the U.S. Department of Energy under contract W-7405-ENG-36. By acceptance of this arvicte, the publisher recognizes that the U.S. Government retains a nonexclusive, royalty-free license to publish or reproduce the published form of this contribution, or to allow others to do so, for U.S. Government purposes. Los Alamos National Laboratory requests that the publisher identify this article others to do so, for U.S. Government purposes. Los Alamos National Laboratory requests that the publsher ldentify this articlo academic freedom and a researcher's right to publish; as an institution, however, the Laboratory does not endorse the viewpoint of a publication or guarantee its technical conectness. 


\section{DISCLAIMER}

This report was prepared as an account of work sponsored by an agency of the United States Government. Neither the United States Government nor any agency thereof, nor any of their empioyees, makes any warranty, express or implied, or assumes any legal liability or responsibility for the accuracy, completeness, or usefulness of any information, apparatus, product, or process disclosed, or represents that its use would not infringe privately owned rights. Reference herein to any specific commercial product, process, or service by trade name, trademark, manufacturer, or otherwise does not necessarily constitute or imply its endorsement, recommendation, or favoring by the United States Government or any agency thereof. The views and opinions of authors expressed herein do not necessarily state or reflect those of the United States Government or any agency thereof. 


\title{
Simulations of the LANL Regenerative Amplifier FEL
}

\author{
M. Kesselring, W.B. Colson, R. Wong, and R.L. Sheffield a \\ Physics Department, Naval Postgraduate School, Monterey, CA 93943 USA \\ a Los Alamos National Lab, MS H851, Los Alamos, NM 87545 USA
}

\begin{abstract}
The LANL regenerative amplifier FEL is designed to produce an average output power of $1 \mathrm{~kW}$. Simulations study the transverse effects due to guiding by the intense electron beam and feedback. These simulations coupled with experimental measurements can be used to improve future high-power FEL designs.
\end{abstract}

This paper discusses simulations of the regenerative amplifier FEL (RAFEL) built at Los Alamos National Lab (LANL). The RAFEL concept is similar to an FEL oscillator design except that less than $1 \%$ of the large signal optical power is fed back. It relies on only a few passes to reach saturation and uses $17 \mathrm{MeV}$ electrons injected into a $2 \mathrm{~m}$ long undulator which is tapered over the last meter. The $30 \%$ taper of the 0.7 Tesla magnetic is field accomplished by increasing the gap size between the magnets along the last meter of the undulator. The downstream mirror reflects a small fraction of the output power through a feedback loop to the upstream mirror where the power seeds the FEL input. The electrons and the majority of the output power pass through holes in the center of the upstream and downstream mirrors.

Simulations were done to explore the parameters of the LANL experiment and develop an understanding of the physics behind the RAFEL design. Simulations used peak currents of $300 \mathrm{~A}$ and $370 \mathrm{~A}$. Fig. 1 shows the output of one of these simulations. The results are for a peak current of $300 \mathrm{~A}$ and $10^{-4}$ feedback. Since this plot is in dimensionless units, the undulator length is defined by the dimensionless time, $\tau$, which goes from zero to one.

The evolution of the optical mode, $|a(x, \tau)|$ shown in the upper-left window of Fig. 1, is dominated by diffraction after the taper is turned on at $\tau=0.5$. The intense electron beam provides guiding over the first

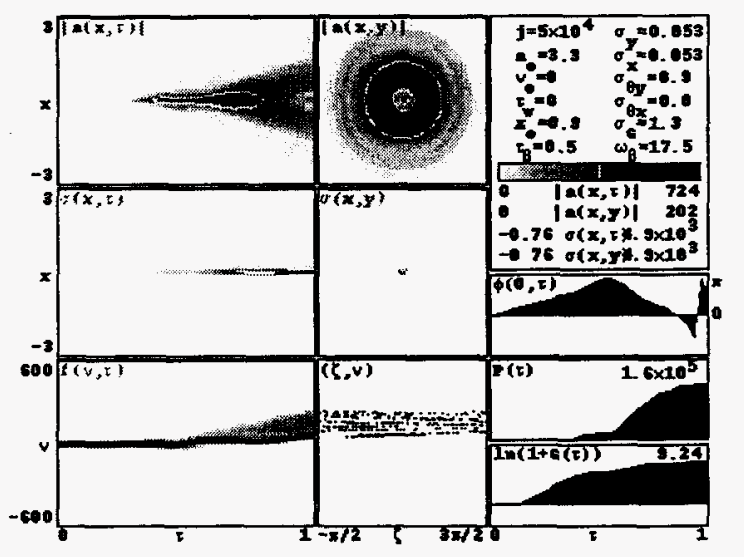

Fig. 1 RAFEL Simulation

meter, but diffraction overcomes this focusing over the last meter of the undulator. The window in the top-center shows a cross-sectional view of the optical mode, $|a(x, y)|$, at the end of the undulator. The top-right window lists the dimensionless parameters for this simulation; an is the initial dimensionless optical amplitude, $\mathrm{j}$ is the dimensionless beam current density, $\sigma_{\mathbf{x}}$ and $\sigma_{\mathbf{y}}$ correspond to the radial size of the electron beam, and $\sigma_{\theta}$ and $\sigma_{G}$ account for beam quality. The 
graph at the right-middle shows the development of the optical phase along the undulator length. When the taper turns on at $\tau=0.5$, the optical phase change along the undulator length becomes negative and encourages the optical wavefront to be excluded from the electron beam decreasing the interaction. At the lower-right is the plot of the dimensionless optical power growth along the undulator and the plot of the natural logarithm of the single pass gain along the undulator. The middle-left window shows the bunching current in the electron beam development along the undulator, with the end view in the center. The bottom-left plot shows the electron phase velocity evolution along the undulator, and at the bottomcenter is the electron phase space plot at the end of the undulator.

In order to optimize gain and efficiency for an FEL about $50 \%$ of the electrons should be trapped [2]. In Fig. 1 much less than half the electrons appear to be trapped as seen in the bottom-center photo. The taper rate in the RAFEL is too large causing detrapping. The $30 \%$ taper of the RAFEL design corresponds to a dimensionless taper of $128 \pi$, but for a peak current of $300 \mathrm{~A}$ the optimal taper rate is $112 \pi$. This increased the efficiency by $2 \%$ and single pass gain by $10 \%$. The same optimization was performed for a peak current of $370 \mathrm{~A}$ realizing an optimal taper rate of $135 \pi$. This provided a slight increase in efficiency and single pass gain. In the $300 \mathrm{~A}$ case decreased taper closes the hole in the center of the optical mode. The change in taper rate allowed for increased optical guiding in the second half of the undulator.

As can be seen in Fig. 1 the optical mode has a drop in optical power in the center for the RAFEL at $300 \mathrm{~A}$. The drop is due to a loss of guiding of the optical mode [2]. Since the electron beam has a small beam radius of $0.18 \mathrm{~mm}$, a rather large current density is necessary for guiding. While guiding occurs initially, when the taper turns on halfway through the undulator diffraction effects begin to take over. The optical mode begins to grow and the change in the optical phase is negative, losing all guiding. In order to prevent this the taper rate must be matched to the peak current. Higher currents can handle a higher taper rate before diffraction effects overcome optical guiding.

The design of this system appears to depend significantly on the amount of feedback. In order to explore the effect of this aspect of the RAFEL, simulations varied the initial dimensionless optical field, a0, from 1 to 130 . The simulation is set up as a steady state representation of an oscillator with the initial optical field determined by the amount of feedback. The inverse of the single pass gain is the amount of the feedback for high gain, or small feedback. Therefore, the variation in feedback during the simulations ranged from about $10^{-1}$ to $10^{-5}$. The feedback throughout this range had almost no effect on efficiency and final power. The efficiency for the $300 \mathrm{~A}$ case was $7 \% \pm 0.5 \%$. The efficiency for the $370 \mathrm{~A}$ case was again within $0.5 \%$ of the average value of $10 \%$. In both instances saturation was reached and output power was essentially the same due to the high gain at the beginning of the RAFEL undulator.

The RAFEL is proposed as a $\mathrm{kW}$-class FEL. Using $17 \mathrm{MeV}$ electrons, $300 \mathrm{~A}$ peak current, a micropulse frequency of $100 \mathrm{MHz}$, a micropulse length of $18 \mathrm{ps}$, a macropulse frequency of $60 \mathrm{~Hz}$, and a macropulse length of $30 \mu$ s gives an electron beam power of $16.5 \mathrm{~kW}$. If an efficiency of $6 \%$ is achieved the resulting power would be a kilowatt. According to simulations the efficiency is high enough in both the $300 \mathrm{~A}$ and $370 \mathrm{~A}$ cases to reach a kilowatt. This observation does not take slippage into account [2].

Several interesting points have come out of these simulations. The simulations showed that for optimal performance the taper starting point should be earlier along the undulator, where the FEL reaches saturation. The amount of feedback in a RAFEL plays a small role in efficiency and final output power over a range of $0.001 \%$ to $10 \%$. The development of a hole in the center of the optical mode can account for lower than expected output, but can be minimized when the taper rate is optimized.

\section{Acknowledgments}

The authors are grateful for the support of this work by LANL, and the Naval Postgraduate School.

\section{References}

[1] R.L. Sheffield, D.C. Nguyen, J.C. Goldstein, N.A. Ebrahim, C.M. Fortgang, and J.M Kinross-Wright, $A$ Compact $1 \mathrm{~kW}$ Infrared Regenerative Amplifier FEL.

[2] W.B. Colson, C. Pellegrini, and A. Renieri, Laser Handbook, North-Holland, 1990. 


\section{M98002666}

Report Number (14) LA- URCONF-970885-

Dubl. Date (11) isonsor Code (18) DOE/MA; DOD, XF JC Category (19) UC- $910 ; 4 C-000, D O E / E R$ 